\title{
Heart Transplant Patients in a wide population observed for Mycophenolic Acid Area Under The Curve executed with a limited sampling strategy technique
}

\author{
Francesco Lo Re ${ }^{1}$, Sandro Sponga ${ }^{1}$, Chiara Nalli ${ }^{1}$, Antonella Zucchetto ${ }^{2}$, Ugolino Livi ${ }^{3}$, and \\ Massimo Baraldo ${ }^{3}$ \\ ${ }^{1}$ University Hospital Santa Maria della Misericordia \\ ${ }^{2}$ Centro di Riferimento Oncologico IRCCS \\ ${ }^{3}$ University of Udine
}

April 12, 2021

\begin{abstract}
Aim The study aim is the validation of two algorithms of Limited Sampling Strategy (LSS) for the quantification of Mycophenolic Acid (MPA) Area under the plasma concentration-time curve from 0 to $12 \mathrm{~h}$ (AUC0-12h) in a cohort of non-selected Heart Transplant (HTx) recipients treated, as standard clinical practice, with Mycophenolate Mofetil (MMF) combined with Cyclosporine (CsA), or Tacrolimus (TAC). These two LSSs were previously tested and validated by Baraldo et al. in a cohort of selected HTx recipients 1,2. The value of MPA AUC0-12h (real and estimated with LSSs) among non-rejected (NR) and rejected $(\mathrm{R})$ patients were evaluated. Methods Linear regression and Bland Altman Analysis validated two LSSs methods (named LSS3 and LSS4 by number of blood samples used). The value of MPA AUC0-12h between NR and R patients were compared by Mann-Whitney test. Results The validation reports positive results for LSS3 and LSS4 according to linear regression ( $\mathrm{r}=0.91$ and 0.94 and $\mathrm{R} 2=0.84$ and 0.88 , respectively) and Bland Altman Analysis ( $\mathrm{p}=0.04$ and 0.04 ). There was a difference of borderline statistically significance $(\mathrm{p}=0.06)$ for the median value of MPA AUC0-12h $(\mathrm{mg} \times \mathrm{h} / \mathrm{L})$ between NR and $\mathrm{R}$ patients (46.60; Interquartile Range (IQR): 34.80-64.10 vs 33.70; IQR: 23.60-48.25); whereas the difference was statistically significant for both LSS3 and LSS4 ( $\mathrm{p}=0.03$ and 0.04$)$. Conclusion The capability of these two LSSs to estimate MPA AUC0-12h in cohort of non-selected HTx recipients and the suggestion of a significant difference on MPA AUC0-12h between NR and R patients, confirm the importance of MPA quantification in the clinical field.
\end{abstract}

Title: Heart Transplant Patients in a wide population observed for Mycophenolic Acid Area Under The Curve executed with a limited sampling strategy technique

Authors: F. Lo Re $(\text { PharmD })^{2}$, S. Sponga $(\mathrm{MD}, \mathrm{PhD})^{4}$, C. Nalli $(\mathrm{MD})^{4}$, A. Zucchetto $(\mathrm{PhD})^{5}$, U Livi ${ }^{3,4}$ (Prof, MD) ${ }^{3,4}$, M. Baraldo (Prof, MD) ${ }^{1,2}$

${ }^{1}$ Professor of Pharmacology, Department of Medical Area (DAME), UNIUD, Udine, Italy; ${ }^{2}$ Clinical Pharmacology and Toxicology Institute, "Azienda Sanitaria Universitaria Friuli Centrale" (ASU FC), Udine, Italy; ${ }^{3}$ Professorof Cardiac Surgery, Department of Medical Area (DAME), UNIUD, Udine, Italy; ${ }^{4}$ Department of Cardiothoracic Surgery, "Azienda Sanitaria Universitaria Friuli Centrale" (ASU FC), Udine, Italy; ${ }^{5}$ Scientific Directorate, Centro di Riferimento Oncologico di Aviano (CRO), IRCCS, Aviano (PN), Italy.

\section{CORRESPONDING AUTHOR:}

Massimo Baraldo (Prof, MD) 
Clinical Pharmacology and Toxicology Institute, "Azienda Sanitaria Universitaria Friuli Centrale" (ASU FC), P.le S.Maria della Misericordia, 15, 33100, Udine, Italy

Phone number: +390432559835

Email:massimo.baraldo@uniud.it

The authors confirm that the Principal Investigator for this paper is Prof. Massimo Baraldo, and that he had direct clinical responsibility for patients.

Running title: Estimation of Mycophenolic Acid $\mathrm{AUC}_{0-12 \mathrm{~h}}$ in $\mathrm{HTx}$ patients

KEYWORDS:

Number of words in the main text: 2889

Abstract words: 249

Figure count: 2

Tables Count: 3

\section{What is already known about this subject:}

Many Limited Sampling Strategies (LSSs) for Mycophenolic Acid (MPA), were determined for solid organ transplantation, because of the correlation of MPA exposure and the clinical outcome;

The Therapeutic drug monitoring of MPA is executed mainly in specialized Hospital trough the pre-dose measurement that is not sufficiently predictive of treatment outcome.

\section{What this study adds:}

This study verifies the capability of two LSSs to estimate MPA exposure in a non-selected cohort of Heart Transplant recipients, in a common clinical practice situation, confirming the dependence of MPA exposure with clinical outcome and providing useful tool for routine practice application.

\section{Abstract}

\section{Aim}

The study aim of is the validation of two algorithms of Limited Sampling Strategy (LSS) for the quantification of Mycophenolic Acid (MPA) Area under the plasma concentration-time curve from 0 to $12 \mathrm{~h}\left(\mathrm{AUC}_{0-12 \mathrm{~h}}\right)$ in a cohort of non-selected Heart Transplant (HTx) recipients treated, as standard clinical practice, with Mycophenolate Mofetil (MMF) combined with Cyclosporine (CsA), or Tacrolimus (TAC). These two LSSs were previously tested and validated by Baraldo et al. in a cohort of selected HTx recipients ${ }^{1,2}$.

The value of MPA $\mathrm{AUC}_{0-12 \mathrm{~h}}$ (real and estimated with LSSs) among non-rejected (NR) and rejected (R) patients were evaluated.

\section{Methods}

Linear regression and Bland Altman Analysis validated two LSSs methods (named LSS3 and LSS4 by number of blood samples used). The value of MPA $\mathrm{AUC}_{0-12 \mathrm{~h}}$ between $\mathrm{NR}$ and $\mathrm{R}$ patients were compared by Mann-Whitney test.

\section{Results}

The validation reports positive results for LSS3 and LSS4 according to linear regression $(r=0.91$ and 0.94 and $\mathrm{R}^{2}=0.84$ and 0.88 , respectively) and Bland Altman Analysis ( $p=0.04$ and 0.04 ). There was a difference of borderline statistically significance $(p=0.06)$ for the median value of $\mathrm{MPA} \mathrm{AUC}_{0-12 \mathrm{~h}}(\mathrm{mg} \times \mathrm{h} / \mathrm{L})$ between NR and R patients (46.60; Interquartile Range (IQR): 34.80-64.10 vs 33.70; IQR: 23.60-48.25); whereas the difference was statistically significant for both LSS3 and LSS4 $(p=0.03$ and 0.04$)$. 


\section{Conclusion}

The capability of these two LSSs to estimate MPA $\mathrm{AUC}_{0-12 \mathrm{~h}}$ in cohort of non-selected HTx recipients and the suggestion of a significant difference on MPA $\mathrm{AUC}_{0-12 \mathrm{~h}}$ between $\mathrm{NR}$ and $\mathrm{R}$ patients, confirm the importance of MPA quantification in the clinical field.

\section{Introduction}

Mycophenolate Mofetil (MMF) is a widely used immunosuppressive drug for the treatment of Heart Transplant (HTx $)^{3}$. It is frequently administered in association with Cyclosporine (CsA) or Tacrolimus (TAC) and prednisone. MMF is a pro-drug and after oral administration, is rapidly metabolized to its active form Mycophenolic Acid (MPA), which inhibits inosine-5'-monophosphate dehydrogenase (IMPDH), a key enzyme of the de novo purine synthesis. This block causes the arrest of the proliferation of T- and B-cells ${ }^{4}$. From a Pharmacokinetic (PK) point of view, there is evidence that MMF presents a high inter-subjects and intra-subject variability ${ }^{5}$. After chronic administration, an increase of the MPA exposure after the first 3 months from transplantation was noted. The exposure to the drug could increase from $30-80 \%^{5}$. For this reason, the execution of TDM could be an effective strategy to maximize the efficacy of the treatment also reducing the risk of toxicity. Several studies have suggested the importance of MPA TDM in renal, heart or lung transplants recipients ${ }^{6}{ }^{5}$. It has been evidenced that the PK parameter that better correlates with the treatment outcome is represented by MPA Area under the plasma concentration-time curve from zero to $12 \mathrm{~h}\left(\mathrm{AUC}_{0-12 \mathrm{~h}}\right)^{57}$. For this parameter it was to determine the exact therapeutic range for renal transplant patients (30-60 $\mathrm{mg} \times \mathrm{h} / \mathrm{L})$, but some authors evidenced possible therapeutic thresholds also for thoracic transplant patients ${ }^{8}$. The single time point measurement, indeed, are not sufficiently predictive of patients outcome $^{8}$. It was demonstrated a $>10$-fold range variation in MPA $\mathrm{AUC}_{0-12 \mathrm{~h}}$ dose-normalized between patients in heart, renal and liver transplantation ${ }^{9}$ and several studies show that MPA levels correlate to risk of rejection ${ }^{10} 11$.

LSSs represent an algorithm-based strategy able to predict the entire $\mathrm{AUC}_{0-12 \mathrm{~h}}$ without the necessity of sampling all the time points' concentrations after drug administration, limiting the sampling to a reduced number of time points, usually three or fewer. It has been noted in a recent Consensus Meeting that LSSs represented the most relevant strategies in solid organ transplantation for dosage individualization ${ }^{8}$. Recently, Baraldo et al. resumed the state of the art of MPA LSSs in heart transplant patients ${ }^{12}$. In this retrospective study we validated two algorithms of LSSs, previously tested and validated by Baraldo et al. ${ }^{1}{ }^{2}$, in a heterogeneous cohort of patients treated either with MMF + CsA and MMF + TAC and with different clinical situations. Then, we analyzed patient's MPA $\mathrm{AUC}_{0-12 \mathrm{~h}}$ to verify if this $\mathrm{PK}$ parameter could represent a predictive or prognostic marker in terms of acute cellular rejection (ACR).

\section{Methods}

\section{Study characteristics}

This is an observational, retrospective cohort study. The study was performed at the University Hospital of Udine, in Italy. The study was approved by the Internal Review Board (I.R.B.) of the Commission for the Experimentation and Protection of Human Subjects of the Department of Medical Area of the University of Udine with the protocol number: 036/2020_IRB.

The study includes 35 HTx recipients previously treated as standard clinical practice with MMF + CsA or MMF + TAC, and Prednisone, at the University Hospital of Udine, and routinely monitored for MPA quantification in the period starting from $01 / 01 / 2011$ to $31 / 12 / 2019$. The patients enrolled in the study must be HTx recipients, over the age of 18 years old, and treated with MMF and either CsA or TAC and Prednisone. Patients treated with immunosuppression drugs other than MMF, CsA and TAC, or with the absence of necessary information for the study in the clinical records or with absence of informed consent for clinical, epidemiological research, training and study of pathologies were excluded from the study. All consecutive HTx recipients in the study period who met inclusion/exclusion criteria were included in the analysis. The post-transplantation time ranged from 0.1 to 17.7 years, with a mean of 3 years and a very high 
variability ( \pm 4.5 years). The group patient characteristics are given in Table 1 . All HTx recipients received a standard triple immunosuppressive therapy: MMF in combination with CsA or TAC and prednisone. The posology regimen of MMF varied from 1000 to $3500 \mathrm{mg} /$ day, with a mean of $1785.7 \mathrm{mg} /$ day $( \pm 559.5)$. While the mean CsA dose was $2.4 \mathrm{mg} / \mathrm{kg} /$ day $( \pm 1.2)$ p.o. in 2 divided doses, mean TAC dose was $0.2 \mathrm{mg} / \mathrm{kg} /$ day $( \pm 0.05)$. Patients did not receive drugs known to cause any relevant pharmacokinetic interactions with MPA. Patients were asked to take their usual morning dose of MMF after having a standard meal. Patients had not changed the therapeutic regimen for 30 days and were at the steady state for MMF. After written informed consent was obtained, 8 venous samples were collected for the analysis of MPA plasma concentrations. For MPA assays, blood samples were collected in EDTA tubes at 0 (pre-dose), 0.5, 1.25, 2, 4, 6, 8, and 12 hours after the morning dose. Separation of plasma was performed immediately in a centrifuge at $4^{\circ} \mathrm{C}$. Plasma MPA concentration was measured using validated HPLC/UV method ${ }^{13}$. The laboratory reported the following parameter for the HPLC/UV method used for MPA quantification: limit of detection: $0.1 \mu \mathrm{g} / \mathrm{mL}$; linearity between 0.1 and $40 \mu \mathrm{g} / \mathrm{mL}\left(\mathrm{R}^{2}: 0.9988\right)$; intrabatch imprecision (CV): $3.15 \%, 1.55 \%$, and $1.76 \%$ at MPA plasma concentrations of $1.5,5.0,15.0 \mu \mathrm{g} / \mathrm{mL}$, respectively; inter-batch imprecision (CV): $3.41 \%, 3.21 \%$, and $1.92 \%$ at MPA plasma concentrations of 1.5, 5.0, $15.0 \mu \mathrm{g} / \mathrm{mL}$, respectively; overall inaccuracy (\% Bias) of the procedure: ranged from $8.7 \%$ to $13.6 \%$. All MPA $\mathrm{AUC}_{0-12 \mathrm{~h}}$ values were calculated using the linear trapezoidal rule.

The clinical outcome intended as the incidence of allograft rejection ( $\mathrm{R}$ or NR) were evaluated by the physician through endo-myocardial biopsies executed as standard clinical practice and classified according to the International Society for Heart and Lung Transplantation (ISHLT) standardized grading method ${ }^{14}$. The degree of toxicity will be defined according to the Common Terminology Criteria for Adverse Events (CTCAE v4.0).

\section{Algorithms validation}

The two algorithms used for MPA $\mathrm{AUC}_{0-12 \mathrm{~h}}$ evaluation were the followings: LSS3: $\mathrm{MPA} \mathrm{AUC}_{0-12 \mathrm{~h}}=5.568$ $+0.902 \times \mathrm{C}_{1.25 \mathrm{~h}}+2.022 \times \mathrm{C}_{2 \mathrm{~h}}+4.594 \times \mathrm{C}_{6 \mathrm{~h}}$; LSS4: MPA $\mathrm{AUC}_{0-12 \mathrm{~h}}=3.800+1.015 \times \mathrm{C}_{1.25 \mathrm{~h}}+1.819 \times$ $\mathrm{C}_{2 \mathrm{~h}}+1.566 \times \mathrm{C}_{4 \mathrm{~h}}+3.479 \times \mathrm{C}_{6 \mathrm{~h}}$. We validated the two LSSs methods with linear regression Analysis and Bland Altman Analysis ${ }^{15} 16$. To assessing bias and imprecision of the LSSs, we evaluated the Mean Percentage Prediction Error (ME\%), the Percentage of The Root Mean Squared Prediction Error (RMSE\%), the Median Percentage Predictive Error (MPPE\%), and the Median Absolute Percentage Predictive Error (MAPE\% ${ }^{15}$.

\section{Statistical consideration}

Descriptive statistical analyses were conducted for all the study variables, reporting position (e.g., mean, median) and variability indexes (e.g., min-max, SD, interquartile range). Regarding the primary objectives, the two methods of LSS were validated by linear regression analysis and Bland Altman analysis, as recommended by the literature ${ }^{15}{ }^{16}$. All the analyses were performed with Medcalc Software version 19.7.2 ${ }^{\circledR}(2020$ MedCalc Software Ltd). Regarding linear regression analysis (least square method), slope and intercept were reported with the corresponding $95 \%$ confidence intervals (CI). The $\mathrm{r}$ was calculated to evaluate the linear correlation between numerical variables (considering the following categories for the absolute value of $r(|r|)$ : $<0.5$ weak correlation, $0.5-0.8$ moderate correlation, and $>0.8$ strong correlation). The Coefficient of determination $\left(\mathrm{R}^{2}\right)$ was reported to verify the goodness of fit of the linear regression (it ranges from 0 to 1 , where 1 indicates perfect fit of the regression line).

Regarding the secondary objectives, the real MPA $\mathrm{AUC}_{0-12 \mathrm{~h}}$ values and those calculated with the two LSSs strategy between patients reporting NR and R patients were tested. The non parametric Mann-Whitney test was used to compare the study groups. $P$ values of a 2 -sided test less than 0.05 was considered as statistically significant.

\section{Results}

Patients characteristics

Demographical, anthropometrical, and pharmacological characteristic of patients enrolled in this study are 
resumed in Table 1.35 patients were enrolled into the study, of which $23(65.7 \%)$ were treated with MMF + CsA, and $12(34.3 \%)$ with MMF + TAC. Gender distribution was $28(80 \%)$ male and $7(20 \%)$ female respectively. The patients enrolled presented a normal renal and hepatic functionality.

Of 35 patients treated, 15 patients (42.9\%) experienced ACR of which 10 were treated with MMF + CsA $(66.6 \%)$ and 5 with MMF + TAC (33.3\%). Grade of rejection revealed ranged from mild to severe (grade 1R-3R), and the time of rejection post-transplant present a high variability among the patients enrolled Table 2.

\section{Method Validation}

The performance of the equation for both LSS3 and LSS4 was evaluated determining ME\% and RMSE\% as reported by Scheiner et al. ${ }^{15}$. Furthermore, MPPE\% and the MAPE\% was also determined. A low tendency of underestimation of the value of $\mathrm{AUC}_{0-12 \mathrm{~h}}$ by LSS3 and LSS4 evaluating ME\% for mean values (-4.1\%; $-3.2 \%$, respectively) and MPPE\% for median values (-2.6\%; $-0.6 \%$, respectively) was also evidenced. Precision of LSS3 and LSS4 was tested evaluating RMSE\% for mean values $(19.2 \% ; 15.8 \%$, respectively), and MAPE\% for median values $(13.2 \% ; 11.4 \%$, respectively).

By the evaluation of the linear regression analysis, it was evidenced that both LSS3 and LSS4 methods can effectively predict the values of MPA $\mathrm{AUC}_{0-12 \mathrm{~h}}$ (slope $=1.14 ; 95 \%$ CI: 0.96 to $1.31 ; 1.18 ; 95 \%$ CI: 1.02 to 1.34 ) (intercept $=-1.79 ; 95 \%$ CI: -9.89 to $+6.30 ;-4.18 ; 95 \%$ CI: -11.30 to 2.95 ), for LSS3 and LSS4, respectively. The value of $\mathrm{r}$ stated for both LSSs methods a strong correlation between the real MPA $\mathrm{AUC}_{0-12 \mathrm{~h}}$ and the $\mathrm{AUC}_{0-12 \mathrm{~h}}$ determinate with both LSSs methods (Figure $\left.1 \mathbf{( A )}(\mathbf{C})\right)$. Finally, the $\mathrm{R}^{2}(0.84 ; 0.88$, for LSS3 and LSS4, respectively) indicates a good fit of the regression line for both methods.

Bland Altman analysis for LSS3 and LSS4 revealed positive results for both methods ( $p=0.04$ and 0.04). Bland Altman Plot is reported inFigure 1(B)(D). The plot shows that the data are arranged almost totally within the range $+/-1.96 * \mathrm{SD}$. The visual inspection of the plot does not reveal any particular pattern, thus excluding other types of bias. This was also assessed by analyzing the linear dependence of the dots in the Bland Altman plot using linear regression, reporting the following results for LSS3 and LSS4 respectively ( lope $=0.23 ; 95 \%$ CI: 0.08 to $0.37 ; 0.24 ; 95 \%$ CI: 0.11 to 0.36$)$, and $(r=0.47,0.55)\left(\mathrm{R}^{2}=0.22 ; 0.31\right)$. These results do not indicate linear dependence. This evidence was confirmed by a further analysis performed by eliminating the so-called "outlier", as being the only point very out of the range $+/-1.96$ * SD could tilt the regression line. The results of the analysis highlighted even lower slope, $\mathrm{r}$ and $\mathrm{R}^{2}$ values for LSS3 and LSS4 respectively (slope $=0.12 ; 95 \%$ CI: -0.06 to $0.29 ; 0.13 ; 95 \%$ CI: -0.01 to 0.27$)(\mathrm{r}=0.24 ; 0.31)\left(\mathrm{R}^{2}=\right.$ $0.06 ; 0.10)$. These results confirm that there was no dependence between the mean of the measures and the difference of the measures.

\section{Analysis of patient's data}

Rejection

The demographical and clinical data of patients experiencing ACR are reported in Table 2 . MPA AUC $\mathrm{C}_{0-12 \mathrm{~h}}$ median value $(\mathrm{mg} \times \mathrm{h} / \mathrm{L})$ was within the therapeutic range but in the lowest part.

Even if almost all the MPA $\mathrm{AUC}_{0-12 \mathrm{~h}}$ values were distributed within the range, a difference of borderline statistical significance between MPA $\mathrm{AUC}_{0-12 \mathrm{~h}}$ median values between $\mathrm{NR}$ and $\mathrm{R}$ patients emerged $(p=$ 0.06). (Table 3, Figure 2 (A) ). Whereas differences of statistical significance were obtained with LSS3 and LSS4, respectively $(p=0.02 ; 0.04)$ (Table 3, Figure $\mathbf{2}$ (B) (C) ).

\section{Discussion}

Despite the well-known pharmacological rationale suggesting an important influence of MPA TDM on treatment clinical outcome, the execution of MPA TDM in clinical practice is the debate still ongoing ${ }^{7}$. One of the most practical reasons is the determination of the entire $\mathrm{AUC}_{0-12 \mathrm{~h}}$ which is costly and time consuming. Furthermore, the impact of MPA TDM on HTx patients has not been studied in detail if compared to renal transplant patients, because at this moment larger prospective randomized trials aimed to find the exact 
relationship between exposure and outcome have not been executed. The most up to date systematic review of the literature has been reported by Zuk et al.. It suggests that the relationship between MPA levels and rejection in HTx patients is not totally defined, but that LSS may be a better assessment strategy to prevent rejection than a single-time point model ${ }^{17}$.

In this study two LSSs obtained in a population of HTx patients treated with MMF + CsA, in a heterogenic population of HTx treated either with MMF + CsA or MMF + TAC were validated. Both the two methods revealed to be precise and accurate for the estimation of the entire $\mathrm{AUC}_{0-12 \mathrm{~h}}$ Figure 1 . Furthermore, if we compared the values of ME\% and RMSE\% with the previous validation executed by Baraldo et al. ${ }^{2}$, we evidenced comparable results in terms of ME\% (-4.1\% vs $-4.9 \%$ for LSS3 and $-3,2 \%$ vs-3.6\% for LSS4, respectively) and RMSE\% ( $19.2 \%$ vs $15.9 \%$ for LSS3 and $15.8 \%$ vs $14.0 \%$ for LSS4, respectively). The major value for RMSE\% could be attributable to the heterogeneous features of the population analyzed, but they remain acceptable biometrically. In this field, Ting et al. had executed previously, a validation of Eight LSSs, of which four obtained from lung transplant patients and four from HTx patients by a different research group. The authors evidenced that, despite the LSSs were tested in Lung Transplant patients, they performed well also in a cohort of HTx patients. Precision and bias were within the acceptable limit of $15 \%$ 18.

Despite the small number of patients, from this study it was evidenced that MPA $\mathrm{AUC}_{0-12 \mathrm{~h}}$ represent the best PK parameter to predict the efficacy of MMF treatment, in terms of ACR. For the MPA AUC $0-12 \mathrm{~h}$ parameter, a difference indicating a trend between the median of $\mathrm{MPA} \mathrm{AUC}_{0-12 \mathrm{~h}}$ among $\mathrm{R}$ and $\mathrm{NR}$ patients was emphasized. It was suggested that $\mathrm{NR}$ patients present $\mathrm{MPA} \mathrm{AUC}_{0-12 \mathrm{~h}}$ leaning towards to the upper limit of the therapeutic range in contrast with $\mathrm{R}$ patients that presented $\mathrm{MPA} \mathrm{AUC}_{0-12 \mathrm{~h}}$ values leaning towards the lower limit of the therapeutic range ((Table 3, Figure 2 (A)) These results were also replicated with the $\mathrm{AUC}_{0-12 \mathrm{~h}}$ obtained with LSS3 and LSS4 ((Table 3, Figure 2 (B) (C)). Analogously, De Nofrio et al evidenced in a cohort of $38 \mathrm{HTx}$ recipients, evaluating MPA $\mathrm{AUC}_{0-12 \mathrm{~h}}$ with an abbreviated sampling schedule, a tendency of lower MPA $\mathrm{AUC}_{0-12 \mathrm{~h}}$ values in patients with Grade $2 / 3(p<0.08)$ or Grade 1 rejection $(p<0.05)^{19}$. Moreover, Figurski et al. in a prospective study involving de-novo HTx recipients, evidenced a correlation of the estimated MPA $\mathrm{AUC}_{0-12}$ with rejection very close to significance $(p=0.059)$, suggesting a threshold of $36 \mathrm{mgxh} / \mathrm{L}$ to prevent rejection ${ }^{20}$. Similarly, Woillard et al. found a correlation between MPA $\mathrm{AUC}_{0-12}$ and rejection $(p=0.0122)$, proposing a threshold level of $50 \mathrm{mgxh} / \mathrm{L}^{21}$.

These data emphasizes the utility of LSSs for the estimation of the entire $\mathrm{AUC}_{0-12 \mathrm{~h}}$ in clinical practice. The limits of this study could be represented by: 1) the limited number of patients; 2) the retrospective nature; 3) the heterogeneous features of patients enrolled. This is a relatively small initial study. The retrospective nature of this study was selected and the principal aim was to verify the efficacy of two previously determined LSSs in a selected cohort of patients treated only with MMF + CsA, in a non-controlled population of patients treated at different time from the transplant with MMF combined with CsA or TAC, representing a common clinical practice situation. TDM was not planned to be executed at the same time for all patients enrolled but was executed by clinical decision. This can be a source of bias, because it is known that the exposition of MPA $\mathrm{AUC}_{0-12 \mathrm{~h}}$ could vary extensively among time during MMF treatment, and also co-medications could alter MPA exposure ${ }^{8}{ }^{4}$, but the heterogeneous features of the patients enrolled could give us an exact picture of what could happened generally in clinical practice during an MMF treatment after HTx.

In conclusion this study emphasizes the utility of the MPA TDM after HTx in clinical practice, to optimize the efficacy of therapy in terms of ACR. Because of the dependence of the MPA $\mathrm{AUC}_{0-12 \mathrm{~h}}$ in the development of rejection, the determination of MPA $\mathrm{AUC}_{0-12 \mathrm{~h}}$ by a LSS could represent an efficient assessment in clinical practice to improve the safety and the quality of care of HTx recipients. In this study two LSSs were validated in a heterogeneous cohort of HTx patients, and both resulted to predict accurately and precisely MPA $\mathrm{AUC}_{0-12 \mathrm{~h}}$. For practical reasons, we can state that the LSS3 can represent an efficient strategy for the execution of MPA TDM, because it requires only 3 plasma timing points, and this can save time and cost.

We also emphasize a difference among MPA $\mathrm{AUC}_{0-12 \mathrm{~h}}$ between $\mathrm{NR}$ and $\mathrm{R}$ patients suggesting the importance of MPA TDM after HTx. Nowadays the therapeutic ranges for MPA TDM were determined in large con- 
trolled trials involving renal transplant patients. Future studies in this field are necessary to determine the exact therapeutic ranges in this population, and to provide clinical tools for dosage adaptation to maximize the efficacy of treatment while minimizing the risk of rejection.

At the end the extension of this study with a wide cohort of HTx recipients, and a pre-planned MPA TDM execution, could be necessary to determine a new more precise and accurate LSSs for MPA quantification.

Acknowlegements: The authors thank the healthcare staff of the Clinical Pharmacology and Toxicology Institute, "S. Maria della Misericordia" University Hospital Friuli Centrale, Udine, Italy, for the collection of blood samples and for the analyses performed.

The authors thank Enza Pincente for the English revision of the Manuscript.

Conflict of interest: The authors declare no conflict of interest.

Funding information: The authors received no specific funding for this work.

Data Availability Statement: The data that support the findings of this study are available from the corresponding author upon reasonable request. Some data may not be made available because of privacy or ethical restrictions.

\section{Authorship contributions}

FL, MB and UL designed the study. FL, MB wrote the protocol, executed the study, executed the PK analysis, interpreted the data and wrote the manuscript. FL and AZ performed the statistical analyses and contribute to the interpretation of data. CN and SP contributed to the data collection for the study.

All authors reviewed and edited the manuscript.

\section{References}

1. Baraldo M, Isola M, Feruglio MT, et al. Therapeutic mycophenolic acid monitoring by means of limited sampling strategy in orthotopic heart transplant patients. Transplant Proc . 2005;37(5):2240-2243. doi:10.1016/j.transproceed.2005.03.090

2. Baraldo M, Cojutti PG, Isola M, et al. Validation of limited sampling strategy for estimation of mycophenolic acid exposure during the first year after heart transplantation. Transplant Proc . 2009;41(10):4277-4284. doi:10.1016/j.transproceed.2009.08.077

3. Opelz G, Dohler B, Susal C. Analysis of positive kidney, heart, and liver transplant crossmatches reported to the Collaborative Transplant Study. Hum Immunol . 2009;70(8):627-630. doi:10.1016/j.humimm.2009.04.009

4. Staatz CE, Tett SE. Pharmacology and toxicology of mycophenolate in organ transplant recipients: an update. Arch Toxicol . 2014;88(7):1351-1389. doi:10.1007/s00204-014-1247-1

5. Kuypers DRJ, Le Meur Y, Cantarovich M, et al. Consensus report on therapeutic drug monitoring of mycophenolic acid in solid organ transplantation. Clin J Am Soc Nephrol . 2010;5(2):341-358. doi:10.2215/CJN.07111009

6. Dubrey SW, Holt DW, Banner N. Measurement of mycophenolate mofetil plasma levels after heart transplantation and a potential side effect of high levels. Ther Drug Monit . 1999;21(3):325-326. doi:10.1097/00007691-199906000-00013

7. Kiang TKL, Ensom MHH. Therapeutic drug monitoring of mycophenolate in adult solid organ transplant patients: an update. Expert Opin Drug Metab Toxicol . 2016;12(5):545-553. doi:10.1517/17425255.2016.1170806

8. Bergan S, Brunet M, Hesselink DA, et al. Personalized Therapy for Mycophenolate: Consensus Report by the International Association of Therapeutic Drug Monitoring and Clinical Toxicology. Ther Drug Monit 
. 2021;43(2):150-200. doi:10.1097/FTD.0000000000000871

9. Shaw LM, Holt DW, Oellerich M, Meiser B, van Gelder T. Current issues in therapeutic drug monitoring of mycophenolic acid: report of a roundtable discussion. Ther Drug Monit . 2001;23(4):305-315. doi:10.1097/00007691-200108000-00001

10. Yamani MH, Starling RC, Goormastic M, et al. The impact of routine mycophenolate mofetil drug monitoring on the treatment of cardiac allograft rejection. Transplantation . 2000;69(11):2326-2330. doi:10.1097/00007890-200006150-00018

11. Hesse CJ, Vantrimpont P, van Riemsdijk-van Overbeeke IC, van Gelder T, Balk AH, Weimar W. The value of routine monitoring of mycophenolic acid plasma levels after clinical heart transplantation. Transplant Proc . 2001;33(3):2163-2164. doi:10.1016/s0041-1345(01)01927-3

12. Baraldo M, Sponga S, Livi U. Therapeutic Drug Monitoring of Micophenolate Mofetil in Cardiac Transplant Patients by Limited Sampling Strategy: An Update. In: Giuseppe Rescigno and Michael S. Firstenberg, ed. Topics in Heart Failure Management . IntechOpen; 2018. doi:10.5772/intechopen.80027

13. Shaw LM, Korecka M, van Breeman R, Nowak I, Brayman KL. Analysis, pharmacokinetics and therapeutic drug monitoring of mycophenolic acid.Clin Biochem . 1998;31(5):323-328. doi:10.1016/s00099120(98)00050-2

14. Billingham M, Kobashigawa JA. The revised ISHLT heart biopsy grading scale. J Hear lung Transplant Off Publ Int Soc Hear Transplant . 2005;24(11):1709. doi:10.1016/j.healun.2005.03.018

15. Sheiner LB, Beal SL. Some suggestions for measuring predictive performance. J Pharmacokinet Biopharm . 1981;9(4):503-512. doi:10.1007/BF01060893

16. Bland JM, Altman DG. Statistical methods for assessing agreement between two methods of clinical measurement. Lancet (London, England) . 1986;1(8476):307-310.

17. Zuk DM, Pearson GJ. Monitoring of mycophenolate mofetil in orthotopic heart transplant recipients-a systematic review. Transplant Rev (Orlando) . 2009;23(3):171-177. doi:10.1016/j.trre.2009.02.002

18. Ting LSL, Partovi N, Levy RD, Ignaszewski AP, Ensom MHH. Performance of Limited Sampling Strategies for Predicting Mycophenolic Acid Area Under the Curve in Thoracic Transplant Recipients. $J$ Hear Lung Transplant . 2008;27(3):325-328. doi:https://doi.org/10.1016/j.healun.2007.12.009

19. DeNofrio D, Loh E, Kao A, et al. Mycophenolic acid concentrations are associated with cardiac allograft rejection. J Hear lung Transplant Off Publ Int Soc Hear Transplant . 2000;19(11):1071-1076. doi:10.1016/s1053-2498(00)00191-1

20. Figurski MJ, Pawiński T, Goldberg LR, et al. Pharmacokinetic monitoring of mycophenolic acid in heart transplant patients: correlation the side-effects and rejections with pharmacokinetic parameters. Ann Transplant . 2012;17(1):68-78. doi:10.12659/aot.882638

21. Woillard J-B, Saint-Marcoux F, Monchaud C, Youdarène R, Pouche L, Marquet P. Mycophenolic mofetil optimized pharmacokinetic modelling, and exposure-effect associations in adult heart transplant recipients.Pharmacol Res . 2015;99:308-315. doi:10.1016/j.phrs.2015.07.012

Table 1: Demographical and clinical data of the patients enrolled in the study

CLINICAL DATA OF 35 PATIENTS ENROLLED IN THE STUDY

\author{
Age (years) \\ MMF Dose (mg/day) \\ MMF Dose (mg/kg/day) \\ Post Transplantation time (years)
}


$\operatorname{BMI}\left(\mathrm{Kg} / \mathrm{m}^{2}\right)$

ALT (IU/L)

$\operatorname{AST}(\mathrm{IU} / \mathrm{L})$

Bilirubin $(\mathrm{mg} / \mathrm{dL})$

$\mathrm{CrCl}(\mathrm{mL} / \mathrm{min})$

GFR $\left(\mathrm{ml} / \mathrm{min} / 1.73 \mathrm{~m}^{2}\right)$

MPA AUC O-12h $(\mathrm{mg} \times \mathrm{h} / \mathrm{L})$

CsA Dose (mg/day)

CsA Dose (mg/kg/day)

TAC Dose (mg/day)

TAC Dose $(\mathrm{mg} / \mathrm{kg} /$ day $)$

Male (\%)

Female (\%)

Number of patients reporting rejection (\%)

Total Number of patients

$\mathrm{AUC}_{0-12 \mathrm{~h}}$ : Area under the plasma concentration-time curve from zero to 12h; ALT: Alanine Aminotransferase; AST: Aspar

Table 2: Demographical and clinical data of patients reporting rejection

DEMOGRAPHICAL DATA OF 15/35 PATIENTS REPORTING REJECTION

\begin{tabular}{|c|c|c|c|c|}
\hline & Mean & SD & Min & Max \\
\hline $\begin{array}{l}\text { Time of } \\
\text { rejection } \\
\text { post-transplant } \\
\text { (months) }\end{array}$ & 27.4 & 38.3 & 1.5 & 119.4 \\
\hline $\begin{array}{l}\text { MMF Dose } \\
(\mathrm{mg} / \text { day })\end{array}$ & 1600.0 & 430.9 & 1000.0 & 3500.0 \\
\hline $\begin{array}{l}\text { Time of TDM } \\
\text { post-transplant } \\
\text { (years) }\end{array}$ & 2.6 & 3.9 & 0.1 & 13.9 \\
\hline $\begin{array}{l}\text { MPA AUC } \\
(\mathrm{mg} \times \mathrm{h} / \mathrm{L})\end{array}$ & 35.4 & 14.5 & 14.8 & 63.9 \\
\hline $\begin{array}{l}\text { Patients } \\
\text { reporting ACR } \\
\text { ISHLT 1R (\%) }\end{array}$ & $8(53 \%)$ & $8(53 \%)$ & $8(53 \%)$ & $8(53 \%)$ \\
\hline $\begin{array}{l}\text { Patients } \\
\text { reporting ACR } \\
\text { ISHLT 2R (\%) }\end{array}$ & $6(40 \%)$ & $6(40 \%)$ & $6(40 \%)$ & $6(40 \%)$ \\
\hline $\begin{array}{l}\text { Patients } \\
\text { reporting ACR } \\
\text { ISHLT 3R (\%) }\end{array}$ & $1(7 \%)$ & $1(7 \%)$ & $1(7 \%)$ & $1(7 \%)$ \\
\hline
\end{tabular}




\begin{tabular}{|c|c|c|c|c|}
\hline ACR: Acute & ACR: Acute & ACR: Acute & ACR: Acute & ACR: Acute \\
\hline Cellular & Cellular & Cellular & Cellular & Cellular \\
\hline Rejection; & Rejection; & Rejection; & Rejection; & Rejection; \\
\hline $\mathrm{AUC}_{0-12 \mathrm{~h}}$ : Area & $\mathrm{AUC}_{0-12 \mathrm{~h}}:$ Area & $\mathrm{AUC}_{0-12 \mathrm{~h}}:$ Area & $\mathrm{AUC}_{0-12 \mathrm{~h}}:$ Area & $\mathrm{AUC}_{0-12 \mathrm{~h}}:$ Area \\
\hline under the plasma & under the plasma & under the plasma & under the plasma & under the plasma \\
\hline time curve from & time curve from & time curve from & time curve from & time curve from \\
\hline zero to $12 \mathrm{~h}$ & zero to $12 \mathrm{~h} ;$ & zero to $12 \mathrm{~h} ;$ & zero to $12 \mathrm{~h} ;$ & zero to $12 \mathrm{~h} ;$ \\
\hline ISHLT: & ISHLT: & ISHLT: & ISHLT: & ISHLT: \\
\hline International & International & International & International & International \\
\hline $\begin{array}{l}\text { Society for Heart } \\
\text { and Lung }\end{array}$ & $\begin{array}{l}\text { Society for Heart } \\
\text { and Lung }\end{array}$ & $\begin{array}{l}\text { Society for Heart } \\
\text { and Lung }\end{array}$ & $\begin{array}{l}\text { Society for Heart } \\
\text { and Lung }\end{array}$ & $\begin{array}{l}\text { Society for Heart } \\
\text { and Lung }\end{array}$ \\
\hline Transplantation; & Transplantation; & Transplantation; & Transplantation; & Transplantation; \\
\hline 1R: Mild Grade; & 1R: Mild Grade; & 1R: Mild Grade; & 1R: Mild Grade; & 1R: Mild Grade; \\
\hline 2R: Moderate & 2R: Moderate & 2R: Moderate & 2R: Moderate & 2R: Moderate \\
\hline Grade; 3R: Severe & Grade; 3R: Severe & Grade; 3R: Severe & Grade; 3R: Severe & Grade; 3R: Severe \\
\hline Grade; MMF: & Grade; MMF: & Grade; MMF: & Grade; MMF: & Grade; MMF: \\
\hline Mycophenolate & Mycophenolate & Mycophenolate & Mycophenolate & Mycophenolate \\
\hline Mofetil; MPA: & Mofetil; MPA: & Mofetil; MPA: & Mofetil; MPA: & Mofetil; MPA: \\
\hline Mycophenolyc & Mycophenolyc & Mycophenolyc & Mycophenolyc & Mycophenolyc \\
\hline Acid; TDM: & Acid; TDM: & Acid; TDM: & Acid; TDM: & Acid; TDM: \\
\hline Therapeutic Drug & Therapeutic Drug & Therapeutic Drug & Therapeutic Drug & Therapeutic Drug \\
\hline Monitoring. & Monitoring. & Monitoring. & Monitoring. & Monitoring. \\
\hline
\end{tabular}

Table 3: Levels analysis in patients reporting rejection.

LEVELS ANALYSIS IN PATIENTS REPORTING REJECTION (MEDIAN)

\begin{tabular}{|c|c|c|c|c|c|}
\hline & $\begin{array}{l}\text { Non-Rejected } \\
\text { Pts }\end{array}$ & $\begin{array}{l}\text { Non-Rejected } \\
\text { Pts }\end{array}$ & Rejected Pts & Rejected Pts & Rejected Pts \\
\hline & Median & IQR & Median & IQR & $\mathbf{P}$ value* \\
\hline MPA AUC & 46.60 & 34.80 to 64.10 & 33.70 & 23.60 to 48.25 & 0.06 \\
\hline $\begin{array}{l}0-12 h \\
(\mathbf{m g} \times \mathbf{h} / \mathrm{L})\end{array}$ & & & & & \\
\hline $\begin{array}{l}\text { LSS3 } \\
(\mathrm{mg} \times \mathrm{h} / \mathrm{L})\end{array}$ & 44.30 & 34.90 to 52.15 & 25.90 & 22.58 to 45.05 & 0.02 \\
\hline $\begin{array}{l}\text { LSS4 } \\
(\mathbf{m g} \times \mathbf{h} / \mathbf{L})\end{array}$ & 46.00 & 36.05 to 49.35 & 25.90 & 24.33 to 47.38 & 0.04 \\
\hline $\begin{array}{l}\text { Number of } \\
\text { patients }\end{array}$ & 20 & 20 & 15 & 15 & \\
\hline
\end{tabular}




\begin{tabular}{|c|c|c|c|c|c|}
\hline $\mathrm{AUC}_{0-12 \mathrm{~h}}:$ & $\mathrm{AUC}_{0-12 \mathrm{~h}}:$ & $\mathrm{AUC}_{0-12 \mathrm{~h}}:$ & $\mathrm{AUC}_{0-12 \mathrm{~h}}:$ & $\mathrm{AUC}_{0-12 \mathrm{~h}}:$ & $\mathrm{AUC}_{0-12 \mathrm{~h}}:$ \\
\hline Area under & Area under & Area under & Area under & Area under & Area under \\
\hline the plasma & the plasma & the plasma & the plasma & the plasma & the plasma \\
\hline $\begin{array}{l}\text { concentration- } \\
\text { time curve }\end{array}$ & $\begin{array}{l}\text { concentration- } \\
\text { time curve }\end{array}$ & $\begin{array}{l}\text { concentration- } \\
\text { time curve }\end{array}$ & $\begin{array}{l}\text { concentration- } \\
\text { time curve }\end{array}$ & $\begin{array}{l}\text { concentration- } \\
\text { time curve }\end{array}$ & $\begin{array}{l}\text { concentration- } \\
\text { time curve }\end{array}$ \\
\hline from zero to & from zero to & from zero to & from zero to & from zero to & from zero to \\
\hline 12h; IQR: & 12h; IQR: & 12h; IQR: & 12h; IQR: & 12h; IQR: & 12h; IQR: \\
\hline Interquartile & Interquartile & Interquartile & Interquartile & Interquartile & Interquartile \\
\hline Range; MPA: & Range; MPA: & Range; MPA: & Range; MPA: & Range; MPA: & Range; MPA: \\
\hline Mycophenolic & Mycophenolic & Mycophenolic & Mycophenolic & Mycophenolic & Mycophenolic \\
\hline Acid; LSS: & Acid; LSS: & Acid; LSS: & Acid; LSS: & Acid; LSS: & Acid; LSS: \\
\hline Limited & Limited & Limited & Limited & Limited & Limited \\
\hline Sampling & Sampling & Sampling & Sampling & Sampling & Sampling \\
\hline Strategy; & Strategy; & Strategy; & Strategy; & Strategy; & Strategy; \\
\hline LSS3: Limited & LSS3: Limited & LSS3: Limited & LSS3: Limited & LSS3: Limited & LSS3: Limited \\
\hline Sampling & Sampling & Sampling & Sampling & Sampling & Sampling \\
\hline $\begin{array}{l}\text { Strategy based } \\
\text { on } 3 \text { plasma }\end{array}$ & $\begin{array}{l}\text { Strategy based } \\
\text { on } 3 \text { plasma }\end{array}$ & $\begin{array}{l}\text { Strategy based } \\
\text { on } 3 \text { plasma }\end{array}$ & $\begin{array}{l}\text { Strategy based } \\
\text { on } 3 \text { plasma }\end{array}$ & $\begin{array}{l}\text { Strategy based } \\
\text { on } 3 \text { plasma }\end{array}$ & $\begin{array}{l}\text { Strategy based } \\
\text { on } 3 \text { plasma }\end{array}$ \\
\hline concentration & concentration & concentration & concentration & concentration & concentration \\
\hline time point; ; & time point; ; & time point; ; & time point; ; & time point; ; & time point; ; \\
\hline LSS4: Limited & LSS4: Limited & LSS4: Limited & LSS4: Limited & LSS4: Limited & LSS4: Limited \\
\hline Sampling & Sampling & Sampling & Sampling & Sampling & Sampling \\
\hline Strategy based & Strategy based & Strategy based & Strategy based & Strategy based & Strategy based \\
\hline concentration & concentration & concentration & concentration & concentration & concentration \\
\hline time point; & time point; & time point; & time point; & time point; & time point; \\
\hline *Mann- & ${ }^{*}$ Mann- & *Mann- & ${ }^{*}$ Mann- & ${ }^{*}$ Mann- & *Mann- \\
\hline Whitney & Whitney & Whitney & Whitney & Whitney & Whitney \\
\hline Test & Test & Test & Test & Test & Test \\
\hline
\end{tabular}

\section{FIGURE LEGENDS:}

Figure 1: Linear regression scatter diagram, Bland Altman Plot of LSS3 and LSS4 respectively.

$\mathrm{AUC}_{0-12 \mathrm{~h}}$ : Area under the plasma concentration-time curve from zero to 12h; MPA: Mycophenolic Acid; LSS: Limited Sampling Strategy; LSS3: Limited Sampling Strategy based on three plasma concentration sampling point; LSS4: Limited Sampling Strategy based on four plasma concentration sampling point, r: coefficient of determination,

Figure 2: Comparison of median entire MPA $\mathrm{AUC}_{0-12 \mathrm{~h}}(\mathrm{mg} \times \mathrm{h} / \mathrm{L})$ and of those calculated with LSS3 and LSS4 between non rejected patients and rejected patients and corresponding $p$-value of the Mann-Whitney test. Median values of $\mathrm{AUC}_{0-12 \mathrm{~h}}$ with the corresponding $95 \%$ confidence intervals (bars). The interval between the dotted lines represents the therapeutic range $(30-60 \mathrm{mg} \times \mathrm{h} / \mathrm{L})$. Dots represent the outliers.

$\mathrm{AUC}_{0-12 \mathrm{~h}}$ : Area under the plasma concentration-time curve from zero to 12h;MPA: Mycophenolic Acid, LSS: Limited Sampling Strategy; LSS3: Limited Sampling Strategy based on three plasma concentration sampling point; LSS4: Limited Sampling Strategy based on four plasma concentration sampling point. 
A) Linear Regression Scatter Diagram LSS3

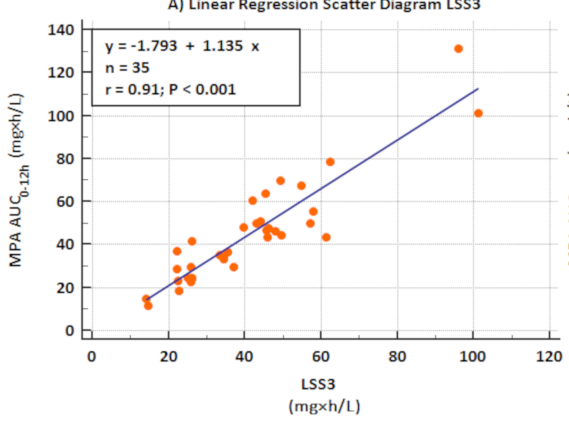

C) Bland Altman Plot LSS3

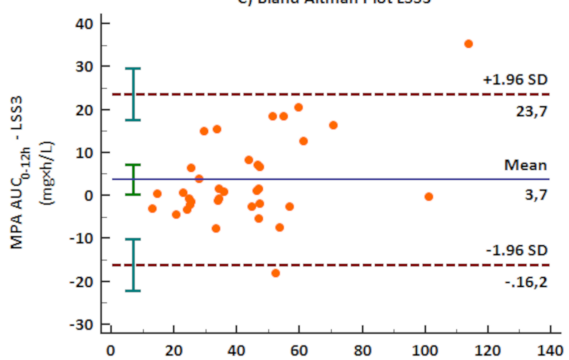

A) COMPARISON OF MEDIAN MPA AUC $\mathrm{C}_{0-12}$ BETWEEN NON REJECTED AND REJECTED PATIENTS

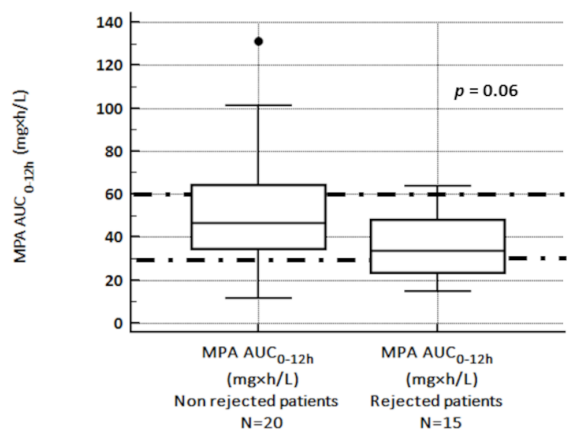

C) COMPARISON OF MEDIAN LSS4 BETWEEN NON REJECTED AND REJECTED PATIENTS

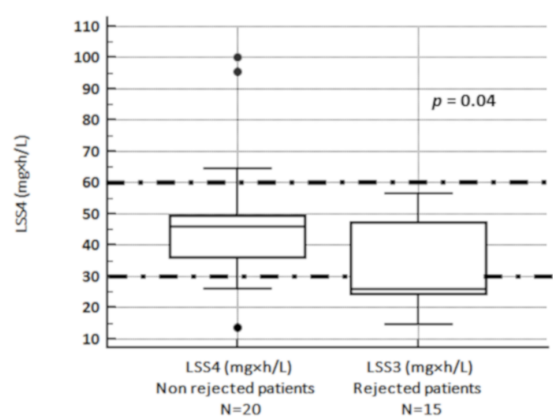

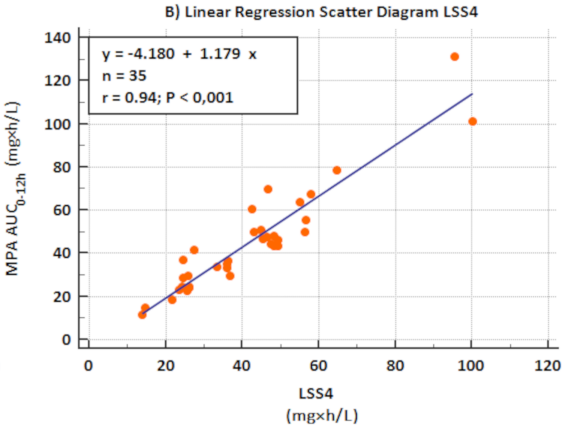

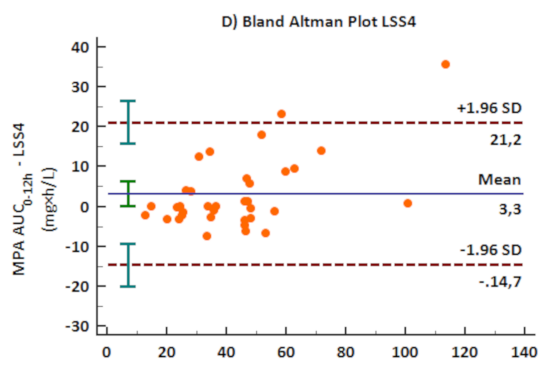

B) COMPARISON OF MEDIAN LSS3 BETWEEN NON REJECTED AND REJECTED PATIENTS

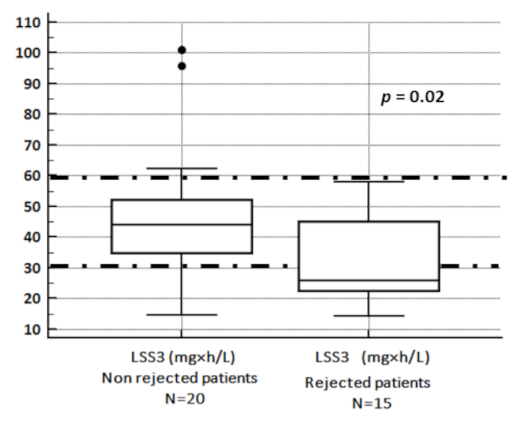

